\title{
Building knowledge-creation for making business competition atmosphere in SMEs of Batik
}

\author{
Nizar Alam Hamdani ${ }^{\mathbf{a}^{*}}$
}

${ }^{a}$ Universitas Garut, Indonesia

\begin{tabular}{|c|c|}
\hline$\overline{\text { CH R O N I C LE }}$ & ABSTRACT \\
\hline $\begin{array}{l}\text { Article history: } \\
\text { Received: November 26, } 2017 \\
\text { Received in revised format: Janu- } \\
\text { ary } 31,2018 \\
\text { Accepted: April 7, } 2018 \\
\text { Available online: } \\
\text { April 8, 2018 } \\
\text { Keywords: } \\
\text { Knowledge-Creation } \\
\text { The strength of competition } \\
\text { Technology } \\
\text { Business orientation }\end{array}$ & $\begin{array}{l}\text { Small and medium sized enterprises (SMEs) of Batik play strategic roles such as a substance, a } \\
\text { mover, and a buffer of the nation's economy and supporting the national economic growth sus- } \\
\text { tainably. However, these SMEs have not been able to compete in both national and international } \\
\text { levels. This is caused by the low rate of knowledge-creation. In line with this, this study aims to } \\
\text { reveal how the knowledge-creation can create the competition atmosphere of the SMEs with the } \\
\text { support from technology and entrepreneurship orientation. Additionally, the methodology em- } \\
\text { ployed in this study was explanatory survey design, with } 286 \text { Batik business units as sample. More } \\
\text { specifically, the sampling technique to select the target area was non-probability in form of pur- } \\
\text { posive sampling. The data were then analyzed using Structural Equation Modeling (SEM). Further, } \\
\text { the result of this study reveals that knowledge-creation influences on creating the business compe- } \\
\text { tition atmosphere with the support of the technology and entrepreneurship and orientation. Based } \\
\text { on the research finding, SMEs Batik finds it difficult to organize the collection of Explicit } \\
\text { Knowledge into a more systematic media, due to the lack of media infrastructure to keep the } \\
\text { knowledge. In addition, technology adoption is not necessary for handmade batik by considering } \\
\text { that handmade batik relies on personal skill. }\end{array}$ \\
\hline
\end{tabular}

\section{Introduction}

The bigger the number of entrepreneurs in a country, the more the economic growth. It takes at least $2 \%$ of the total population in order for a country to become a developed country. This number has yet to be achieved by Indonesia. In 2014, the number of entrepreneurs in Indonesia is as few as $1.5 \%$ of its total population, far left behind other countries in Southeast Asia like Singapore and Malaysia. Of its total population, the number of entrepreneurs in Singapore has reached 7\% (Hasan, 1934; Schumpter, 1934). Entrepreneurship plays an important role in encouraging the competitiveness and economic growth of a country and is a significant source of social mobility. The fact that entrepreneurs play such roles as innovators, agents of change in the market, and competition creators indicates that entrepreneurship contributes to economic performance of a country. Experts in management emphasize the important role of entrepreneurs as economic growth drivers: "entrepreneurship is driving force behind economic growth" (Dean \& McMullen, 2007; Ghorbel et al., 2017).

\footnotetext{
* Corresponding author

E-mail address: nizar_hamdani@uniga.ac.id (N. A. Hamdani) 
Global Entrepreneur Index measurement of entrepreneurial success rate in the development of SMEs shows that Indonesia's GEI rank is still far below other countries. This index measures the quality and the scale of entrepreneurial process in 132 countries worldwide. The indicators used by GEI include entrepreneurial attitude, ability, technology, innovation and aspiration. The data and the contribution they make to the process of creating a business are justified by three decades of research on entrepreneurship in many countries. The results of the research conducted by GEDI show that Indonesia is ranked $103^{\text {rd }}$ with a score of 22.8 (Autio, 2016). Studies carried out in Latin American countries have proved that the growth rate of entrepreneurship can improve their competitiveness indicators, which in turn are likely to become the key factors in achieving the next stage of their development. Put it another way, countries with positive entrepreneurial factors will have positive competitiveness (Singer et al., 2015). In developing countries, the dynamics of entrepreneurship can help transition "the managed economies" to "the entrepreneurial economies" (Ács \& Audretsch, 2010). Other empirical studies carried out in various countries in different periods reveal the existence of different kinds of relations between an entrepreneur, efficiency driving factors, and innovation driving factors (Evangelista et al., 2010). Small and medium sized enterprises (SMEs) play an important role in the Indonesian economy because these sectors can overcome the equity concerns in the distribution of regional incomes. What's more, SMEs have managed to survive and continue to thrive in the midst of the crisis because in general these sectors are still utilizing local resources, be it human resources, capitals, raw materials, or equipment, meaning that SMEs do not need to rely on imported goods. The number of SMEs as of 2015 is estimated to reach $3,615,650$ business units. In other words, there is an increase of $2.6 \%$ from that in 2014; i.e., 3,522,851 business units. Concerning the development of SMEs in Indonesia, there has been an increase every year during the period 2010 - 2015 although it has always been below 5\% (BPS, 2016).

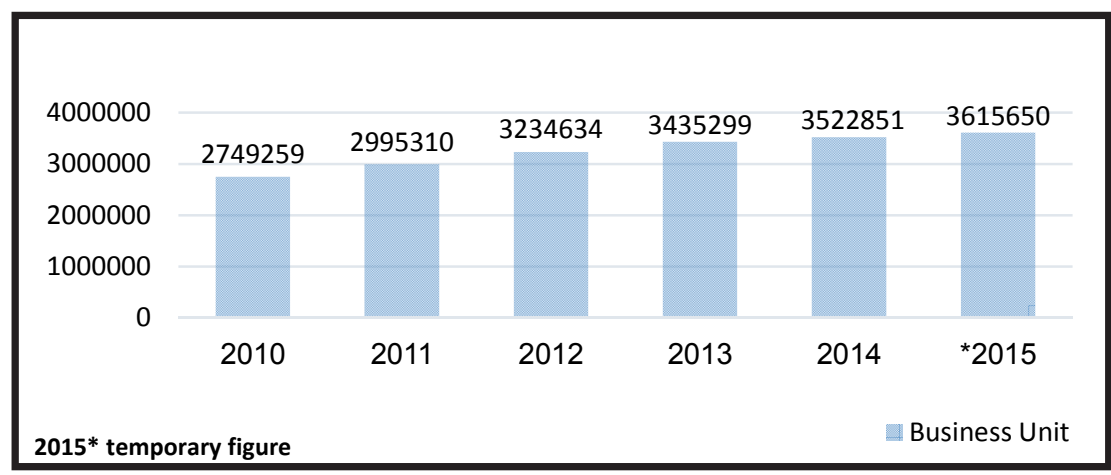

Fig. 1. The development of SMEs in Indonesia in 2010 - 2015

The last cycle of an SME (that is competitive, plays a significant role in strengthening the national business structure, contribute to the poverty reduction through the expansion of employment opportunities, and produces goods and / or business service to be exported) is to convey the offer to the target market, both domestic and overseas, that results in the sustainable sales that are profitable for both sellers and the buyers.

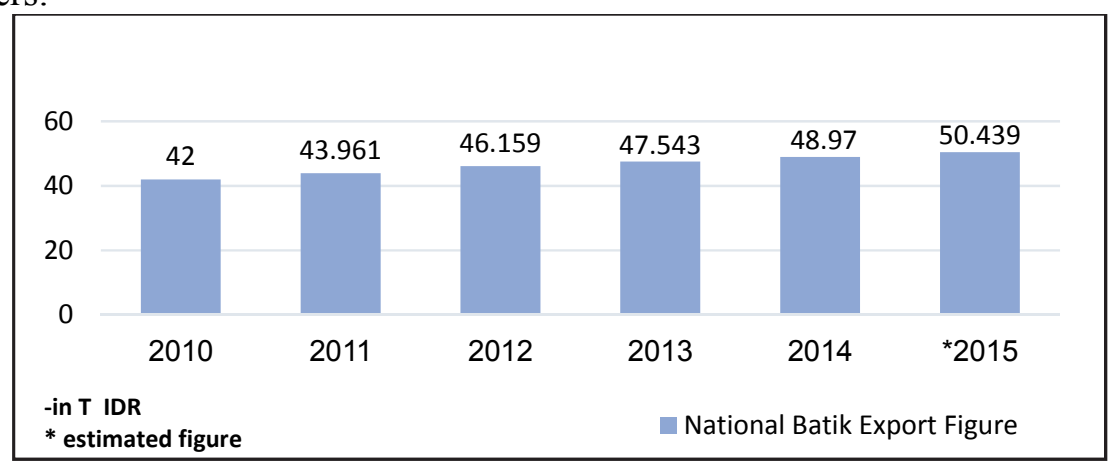

Fig. 2. Batik Export Figure Records 
The market opportunities for Indonesian batik in the domestic market include not only fashions but also interior households, handicraft materials, shoes, bags, and accessories such as wallets and ties. Among the potential overseas markets for Indonesian batik are the United States, Sweden, United Arab Emirates and France (Industry, 2016). Generally, there are two factors SMEs deal with, internal and external factors. The internal factors include the access to the market and to bank capitalization, management, and the quality of human resources. The external factors include non-conducive business climates, inadequate infrastructures, the high-cost economy, negative impacts of regional autonomy, and limited access to the information. Another problem SMEs encounter is the lack of competitiveness. This is one of neglected research areas concerning SMEs. What causes the poor information technology support includes lack of innovation, expensive Internet access, and limited infrastructure (Raf, 2000). Based on the results of field observation of 10 batik SMEs in West Java on January 1, 2017, it can be concluded that several problems at the center of batik business among others are low creativity in terms of designs, efficiency, and quality. Factors affecting the development of creativity of batik SMEs could be categorized into several variables as follows: (1) creative human resource variables such as motivation, aptitude / interests, communication, and competence; (2) creative work variables such as works, leadership, and entrepreneurship; (3) organizational variables such as company's performance, policy, organizational structures and culture, and communication system; (4) environment variables such as the empowerment of external resources, technology, competition, and government regulation; (5) product innovation variables such as designs, materials, equipment, and the utilization of batik waste. Overall, every variable consist of factors that support the development of creativity.

In addition to knowledge creation, another SMEs Batik problem is something related to technology. It has been reported by Azyabi (2017) stating that in some SMEs, lack of technology literacy has resulted in high production costs and low product differentiation. On the other hand, Adya Hermawati (2017) states that technology transformation in batik industry is needed by batik SMEs in order to increase production efficiency, and create product diversification through technological transformation. Furthermore, Ma'ruf, Sidiq Permono Nugroho (2017) explains good SMEs Batik management can improve the high competitiveness which leads to the economic growth of the region, the provision of employment, poverty and unemployment reduction

\section{Literature Review}

Knowledge management as a basic of knowledge creation is applicable not only to big companies but also to SMEs (Desouza \& Awazu, 2006). Although studies have revealed that knowledge creation and human resources are still low, but the application of knowledge creation can improve the competitiveness and performance of SMEs (Cerchione et al., 2015). Knowledge creation and technology mastery in SMEs are different from the theory of knowledge creation frequently encountered in big companies. Theoretically, experts normally suggest that knowledge creation and technology are only applicable to big companies; however, empirically the application is frequently found in SMEs (Rrustemi, 2011). It is also suggested that technology plays a big role in the development of SMEs (Carr, 2005). In addition, Solek-Borowska (2017) argues that knowledge management needs to be well constructed to support knowledge creation in SMEs. His research also points out that SMEs organization is flat and requires less people and low technology application

Nonaka and Lewin (1994) describe knowledge creation as an "upward spiral process, starting at the individual level, moving up to the collective (group) level, and then to the organizational level, sometimes reaching out to the inter-organizational level." In this respect, there are two kinds of knowledge, tacit and explicit knowledge. Every individual possesses both of them. When social interactions between individual take place, new knowledge is created by itself. This is what-so-called the ontology of knowledge creation (Nonaka \& Lewin, 1994). 


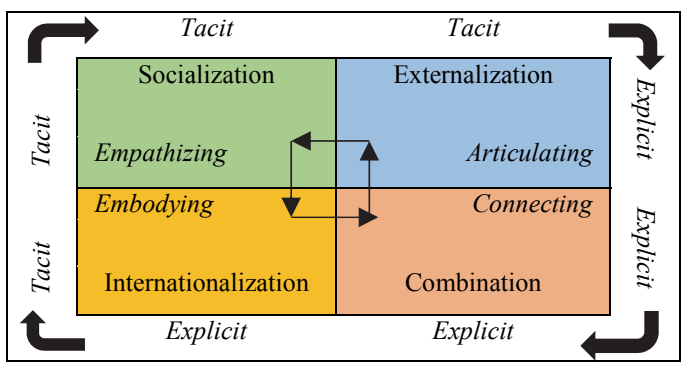

Fig. 3. SECI Model

SECI model of knowledge creation is shown in Fig. 3. According to Nonaka and Lewin (1994), "this model identifies four specific types of knowledge conversion that occur as an individual's tacit knowledge becomes an organization's explicit knowledge: Socialization, Externalization, Combination and Internalization (SECI). The framework enables organizations to anticipate and diagnose where gaps in the process exist and where effort needs to be applied in order to overcome the gaps." This research used Nonaka and Lewin's SECI Model as the framework. The adoption of technology is strongly needed to support the performance and competitiveness of SMEs. The use of information technology plays a very big role, especially when supported by government policies that support the technology sector (Raf, 2000). Cerchione et al. (2015) state that the use of IT provides a support for the management strategies associated with the aspect of communication, access to information, decisionmaking, data management and knowledge management in an organization. IT can be a strategic force and an organizational tool that benefits the promotional aspects and competitiveness (Carr, 2005). IT helps business organizations reduce costs and improve their ability to coordinate with outside parties. In today's knowledge-based economy era, it is important for SMEs to adopt IT because it enables them to provide better and competitive services (Apulu \& Latham, 2011). Entrepreneurship is applicable not only to big companies but also SMEs. Entrepreneurship is a behavior based on concepts and ideas. Everyone who dares to make bold decisions and is actively prepared to deal with problems is capable of being an entrepreneur (Drucker, 1985). This means that business people can be regarded as entrepreneurs only if they can use their creativity to seize the available opportunities and turn them into a profit-making venture. An entrepreneur has to figure out, evaluate, develop an opportunity and a business plan, formulate the required resources and manage his business (Robert \& Michael, 2008).

Similarly, Covin and Slevin (1989) state that values and behaviors of an entrepreneurship orientation include three aspects: innovativeness, risk-taking and pro-activeness. They also put forward that entrepreneurship orientation is measured through four dimensions including autonomy, innovation, risk taking, aggressiveness to compete. According to Kirzner (2015), "entrepreneurship orientation has the following dimensions: opportunity identification and evaluation, risk taking, business management, the development of new ideas in the product, process, and service to boost the company's market share and performance." Another point is explained by Zeebaree and Siron (2017) that entrepreneurial orientation is very influential on the competitiveness of SMEs through financial capabilities. This research used the concept based on Drucker (1985), and Kirzner (2015). The construct established in this research was adjusted to the condition of batik enterprises in West Java. As for the entrepreneurship orientation, this research used four indicators as follows: aggressiveness to compete, proactivity, innovativeness, and risk taking. Kadocsa (2006) mentions that SMEs will be competitive if they have good planning strategies. This includes their ability to project their future. In order for a batik industry to be able to create a competitive advantage, it has to innovate new lines of products that are different from those offered by its competitors. It could be in the form of products with a more attractive packaging that contains the product information, product delivery system, and better service process to customers. Organizational resources and system capabilities will create a competitive advantage. This is in accordance with the results of some studies (Darbanhosseiniamirkhiz \& Wan Ismail, 2012; Bozkurt \& Kalkan, 2014). 
The indicators of the competitive advantage differ from one another. Boston University proposes six variables of competitive advantage including due dates, services, quality, flexibility, cost, and innovation. These instruments have been used in various organizations in the world for more than ten years through a number of experiments and modifications, and hence are valid and credible (Wu, 2015). It could then be said that a competitive advantage is a company or organization's ability to satisfy the needs and expectations of the customers by means of giving more than what their competitors offer. The concept used in this study refers to Raf (2000), and Bozkurt and Kalkan (2014). The construct established in this study was adjusted to the indicators contained in the competitiveness of batik SMEs. These indicators include product benefits, service benefits, image benefits, and cost benefits. The indicators of batik SMEs' competitiveness in West Java are realized in the product benefits, service benefits for the customers, image benefits, and cost benefits.

\section{Methodology/Materials}

This study used a descriptive explanatory survey method. The unit of analysis includes small and medium-sized enterprises in the sector of batik industry in West Java Province. The samples were the 286 owners of batik SMEs in West Java, this SMEs included handmade batik and printed batik, selected using a non-probability purposive sampling with specific criteria from the population of as many as 9,527 batik SMEs. The sample size was determined in accordance with the minimum size of SEM analysis. The data collection techniques used in this study are literature study, interviews to the SMEs owners and questionnaires consisting of the three observed variables.

This study used SECI model (Nonaka \& Lewin, 1994) as the knowledge creation include (1) socialization, (2) externalization, (3) Combination and (4) Internalization (2) Socialization, Externalization, The indicators for the technology variable include (1) the characteristics of SMEs, (2) SMEs' strategies and competition management, (3) the influence of internal and external parties on the decision-making process of technology adoption, and (4) the characteristics of new technology to be adopted. The indicators for the entrepreneurship orientation include (1) the aggressiveness to compete, (2) proactivity, (3) innovativeness, and (4) risk taking. The indicators for the competitive capability including (1) product benefits, (2) service benefits, (3) image benefits, and (4) cost benefits.

\section{Results and Findings}

Several tests were carried out to measure the latent and manifest variables. The result is summarized in Table 1 as follows:

Table 1

Results of CFA Test of Entre Orientation and Technology against Knowledge Creation

\begin{tabular}{|c|c|c|c|c|c|c|}
\hline Latent Variable & $\begin{array}{l}\text { Manifest Vari- } \\
\text { able }\end{array}$ & $\Lambda$ & $\lambda 2$ & e & $\mathrm{CR}$ & $\mathrm{VE}$ \\
\hline \multirow{4}{*}{ Entre Orientation } & Agg & 0.735 & 0.540 & 0.460 & \multirow{4}{*}{0.816} & \multirow{4}{*}{0.526} \\
\hline & Pro & 0.702 & 0.493 & 0.507 & & \\
\hline & Inn & 0.761 & 0.579 & 0.421 & & \\
\hline & Risk & 0.700 & 0.490 & 0.510 & & \\
\hline \multirow{4}{*}{ Technology } & Cha & 0.979 & 0.958 & 0.042 & \multirow{4}{*}{0.919} & \multirow{4}{*}{0.745} \\
\hline & Stra & 0.665 & 0.442 & 0.558 & & \\
\hline & Inf & 0.998 & 0.996 & 0.004 & & \\
\hline & Tech & 0.764 & 0.584 & 0.416 & & \\
\hline \multirow{4}{*}{ Knowledge Creation } & Soc & 0.986 & 0.972 & 0.028 & \multirow{4}{*}{0.911} & \multirow{4}{*}{0.72} \\
\hline & Ext & 0.700 & 0.490 & 0.510 & & \\
\hline & Comb & 0.692 & 0.479 & 0.521 & & \\
\hline & Inter & 0.977 & 0.955 & 0.045 & & \\
\hline
\end{tabular}


The above table shows that the loading factors of all manifest variables are $(\lambda) \geq 0.5$. This entails that all manifest variables are valid, and hence have meanings in measuring the latent variables. The $\lambda^{2}$ value is to indicate how far each indicator correlated to the latent variables. The $\lambda^{2} \mathrm{Agg}$ manifest variable value was 0.735 , meaning that the question items of Agg correlated with the Entre Orientation variable as much as $73.5 \%$. The $\lambda^{2}$ Pro manifest variable value was 0.702 , meaning that the question items of Pro correlated with the Entre Orientation variable as much as $70.2 \%$. The $\lambda^{2}$ Inn manifest variable value was 0.761 , meaning that the question items of Inn correlated with the Entre Orientation variable as much as $76.1 \%$. The $\lambda^{2}$ Risk manifest variable value was 0.700 , meaning that the question items of Risk correlated with the Entre Orientation variable as much as $70 \%$. The CR value $>0.7$ and $\mathrm{VE}>0.5$ indicates that the question items in the questionnaire used to measure the latent variables were consistent and reliable. The result of Goodness of Fit calculation of the Entre Orientation, Technology and Knowledge Creation against the Competitiveness is as follows: The X2/df value of the studied model was 3.875 with the p-value $=0.000$. The obtained results show that the X2/df test was Good Fit, and hence the model satisfied the criteria.

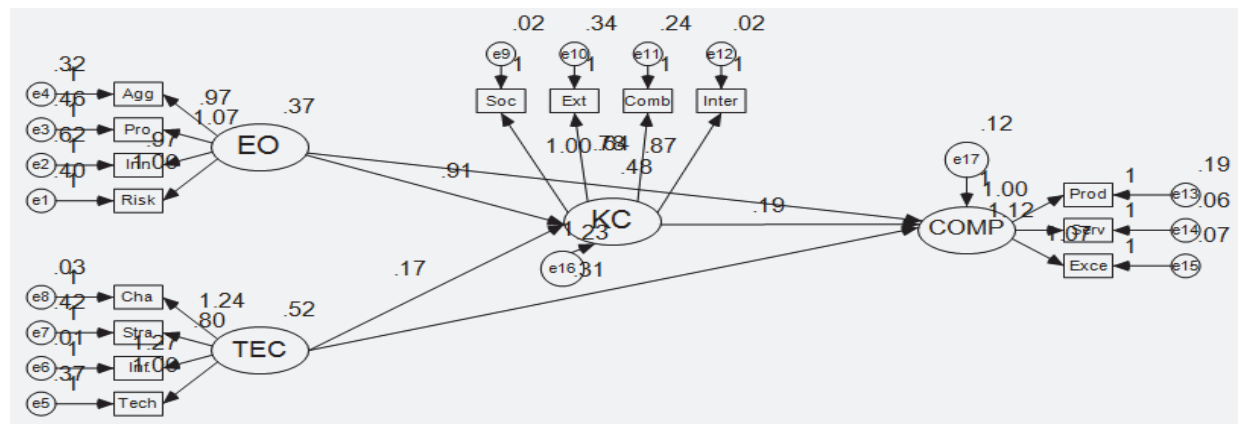

Fig. 4. Results of CFA Test of Entre Orientation, Technology, and Knowledge Creation against Competitiveness

The model had to be modified because, with reference to GOF, it was not Fit. The modification result is as follows:

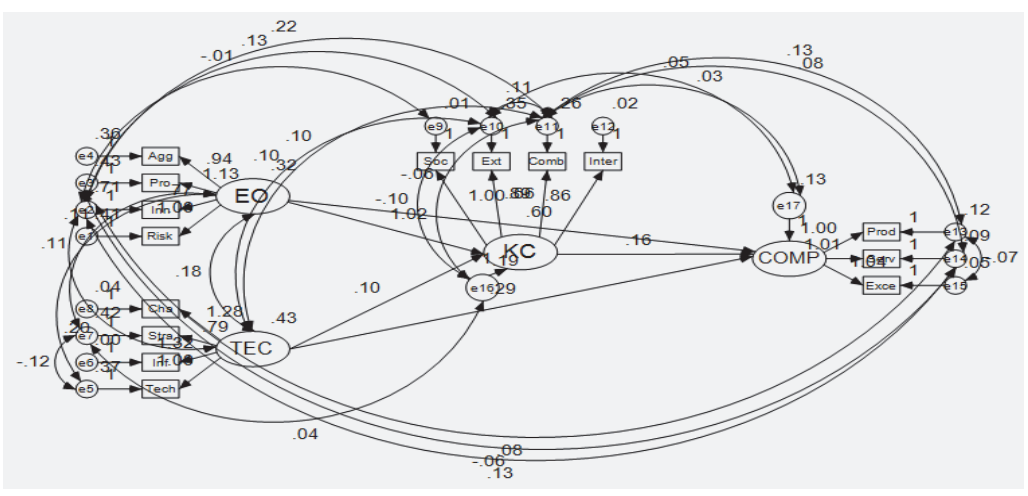

Fig. 5. The modified CFA Test of Entre Orientation, Technology, and Knowledge Creation against Competitiveness

Table 2 shows that the loading factors of all manifest variables are $(\lambda) \geq 0.5$. This entails that all manifest variables are valid, and hence have meanings in measuring the latent variables. The $\lambda^{2}$ value is to indicate how far each indicator correlated to the latent variables. The $\lambda^{2} \mathrm{Agg}$ manifest variable value was 0.767, meaning that the question items of Agg correlated with the Entre Orientation variable as much as $76.7 \%$. The $\lambda^{2}$ Pro manifest variable value was 0.695 , meaning that the question items of Pro correlated with the Entre Orientation variable as much as $69.5 \%$. The $\lambda^{2} \operatorname{Inn}$ manifest variable value was 0.760 , meaning that the question items of Inn correlated with the Entre Orientation variable as much as 
$76 \%$. The $\lambda^{2}$ Risk manifest variable value was 0.661 , meaning that the question items of Risk correlated with the Entre Orientation variable as much as $66.1 \%$. The CR value $>0.7$ and $\mathrm{VE}>0.5$ indicates that the question items in the questionnaire used to measure the latent variables were consistent and reliable.

Table 2

Results of the modified CFA Test of Entre Orientation, Technology, Knowledge Creation against Competitiveness

\begin{tabular}{|c|c|c|c|c|c|c|}
\hline Latent Variable & $\begin{array}{c}\text { Manifest Var- } \\
\text { iable }\end{array}$ & $\lambda$ & $\lambda 2$ & $\mathbf{e}$ & $\mathbf{C R}$ & VE \\
\hline \multirow{4}{*}{ Entre Orientation } & Agg & 0.767 & 0.588 & 0.412 & \multirow{4}{*}{0.813} & \multirow{4}{*}{0.521} \\
\hline & Pro & 0.695 & 0.483 & 0.517 & & \\
\hline & Inn & 0.760 & 0.578 & 0.422 & & \\
\hline & Risk & 0.661 & 0.437 & 0.563 & & \\
\hline \multirow{4}{*}{ Technology } & Cha & 0.976 & 0.953 & 0.047 & \multirow{4}{*}{0.908} & \multirow{4}{*}{0.719} \\
\hline & Stra & 0.623 & 0.388 & 0.612 & & \\
\hline & Inf & 0.999 & 0.998 & 0.002 & & \\
\hline & Tech & 0.732 & 0.536 & 0.464 & & \\
\hline \multirow{4}{*}{ Knowledge Creation } & Soc & 0.993 & 0.986 & 0.014 & \multirow{4}{*}{0.938} & \multirow{4}{*}{0.793} \\
\hline & Ext & 0.828 & 0.686 & 0.314 & & \\
\hline & Comb & 0.745 & 0.555 & 0.445 & & \\
\hline & Inter & 0.972 & 0.945 & 0.055 & & \\
\hline \multirow{3}{*}{ Competitiveness } & Prod & 0.887 & 0.787 & 0.213 & \multirow{3}{*}{0.941} & \multirow{3}{*}{0.841} \\
\hline & Serv & 0.912 & 0.832 & 0.168 & & \\
\hline & Exce & 0.951 & 0.904 & 0.096 & & \\
\hline
\end{tabular}

The $\lambda^{2}$ Cha manifest variable value was 0.976 , meaning that question items of Cha correlated with the Technology variable as much as $76.1 \%$. The $\lambda^{2}$ Stra manifest variable value was 0.623 , meaning that question items of Stra correlated with the Technology variable as much as $62.3 \%$. The $\lambda^{2}$ Tech manifest variable value was 0.999 , meaning that question items of Cha correlated with the Technology variable as much as $99.9 \%$. The $\lambda^{2}$ Tech manifest variable value was 0.732 , meaning that question items of Cha correlated with the Technology variable as much as $73.2 \%$. The $\mathrm{CR}$ value $>0.7$ and $\mathrm{VE}>0.5$ indicates that the question items in the questionnaire used to measure the latent variables were consistent and reliable.

Table 3

Results of the modified CFA Test of Entre Orientation, Technology, Knowledge Creation against Competitiveness

\begin{tabular}{|c|c|c|c|c|}
\hline Fit Indicator & Recommended Value & Model Evaluation & $\begin{array}{l}\text { The Results of the } \\
\text { Study }\end{array}$ & Note \\
\hline Probability & $\mathrm{P}>0.05$ & Not Significant & 0.000 & Not Significant \\
\hline \multirow{2}{*}{ Normed Chi Square $\left(\mathrm{x}^{2} / \mathrm{df}\right)$} & $<2$ & Over Fitting & \multirow{2}{*}{3.875} & \multirow{2}{*}{ Good Fit } \\
\hline & $2<\mathrm{x}^{2} / \mathrm{df}<5$ & Good Fit & & \\
\hline \multirow{3}{*}{ RMSEA } & $<0.10$ & Good Fit & \multirow{3}{*}{0.100} & \multirow{3}{*}{ Bad Fit } \\
\hline & $<0.05$ & Very Good Fit & & \\
\hline & $<0.01$ & Outstanding Fir & & \\
\hline RMR & $<0.05$ & Good Fit & 0.077 & Bad Fit \\
\hline NFI & $>0.90$ & Good Fit & 0.953 & Good Fit \\
\hline CFI & $>0.90$ & Good Fit & 0.964 & Good Fit \\
\hline RFI & $>0.90$ & Good Fit & 0.921 & Good Fit \\
\hline IFI & $>0.90$ & Good Fit & 0.965 & Good Fit \\
\hline \multicolumn{5}{|l|}{ Parsimonious Fit } \\
\hline PNFI & $0-1$ & The higher, the better & 0.572 & The higher, the better \\
\hline PGFI & $0-1$ & The higher, the better & 0.478 & The higher, the better \\
\hline
\end{tabular}

The $\lambda^{2}$ Soc manifest variable value was 0.993 , meaning that question items of Stra correlated with the Knowledge Creation variable as much as $99.3 \%$. The $\lambda^{2}$ Ext manifest variable value was 0.828 , meaning that question items of Stra correlated with the Knowledge Creation variable as much as $82.8 \%$.The $\lambda^{2} \mathrm{Comb}$ manifest variable value was 0.745 , meaning that question items of Comb correlated with the 
Knowledge Creation variable as much as $74.5 \%$. The $\lambda^{2}$ Inter manifest variable value was 0.972 , meaning that question items of Stra correlated with the Knowledge Creation variable as much as 97.2\%.The $\mathrm{CR}$ value $>0.7$ and $\mathrm{VE}>0.5$ indicates that the question items in the questionnaire used to measure the latent variables were consistent and reliable.

The $\lambda^{2}$ Prod manifest variable value was 0.887 , meaning that the question items of Prod correlated with the Competitiveness variable as much as $88.7 \%$. The $\lambda^{2}$ Serv manifest variable value was 0.912 , meaning that the question items of Prod correlated with the Competitiveness variable as much as $91.2 \%$.The $\lambda^{2}$ Exce manifest variable value was 0.951 , meaning that the question items of Exce correlated with the Competitiveness variable as much as $95.1 \%$. The CR value $>0.7$ and VE $>0.5$ indicates that the question items in the questionnaire used to measure the latent variables were consistent and reliable. The result of Goodness of Fit calculation of the Entre Orientation, Technology and Knowledge Creation against the Competitiveness is as follows: The X2/df value of the studied model was 3.875 with the pvalue $=0.000$. The obtained results show that the X2/df test was Good Fit, and hence the model satisfied the criteria. The RMSEA (Root Mean Square Error of Approximation) value of the studied model was 0.100 .The recommended RMSEA value is $\leq 0.05$ close fit and $0.05<$ RMSEA $\leq 0.08$ good fit. If the RMSEA value is between $0.08-0.10$, it is a marginal fit, and the value of $>10$ indicates a poor fit. This measure shows the expected goodness of fit when the model is estimated in the population. The RMSEA value is a measure to fix the Chi-square statistical tendencies that reject a big sized model. The RMSEA value of $>0.100$ indicates a poor fit model (based on the degree of freedom in the model).

Based on the second criterion, the NFI (Normed Fit Index) of the research model is 0.953 , which could be regarded as a Good Fit. The obtained Comparative Fit Index (CFI) of the model was 0.964, which was Good Fit, its Relative Fit Index (RFI) was 0.921 which was Good Fit, its Incremental Fit Index (IFI) was 0.965 which was Good Fit, and its Root Mean Square Residual (RMR) was 0.077 which was Bad Fit. Based on the third criterion, the model's Parsimonious Normed Fit Index (PNFI) of 0.572 and the Parsimonious Goodness of Fit Index (PGFI) of 0.478 show the goodness of fit. As matters stand, the results of the test shows that the model satisfied the goodness of fit measure, and hence was appropriate and accepted.

\section{The Influence of Entre Orientation on Knowledge Creation}

$\mathrm{H}_{0}: \gamma_{1}=0$; Entre Orientation has no influence on Knowledge Creation;

$\mathrm{H}_{1}: \gamma_{1} \neq 0$; Entre Orientation has influence on Knowledge Creation

The obtained equation is as follows:

Knowledge Creation $=0.771 *$ Entre Orientation, $S . E=0.109, C . R=9.439$

This indicates that the coefficient of the exogenous latent variable, Entre Orientation, $\left(\xi_{1}\right)$ against the endogenous latent variable, Knowledge Creation, $(\eta)$ was 0.771 . In other words, there was a strong correlation between Entre Orientation and Knowledge Creation. The observed $t$ value was 9.439, higher than the critical $t$ at 1.96. Thus $\mathrm{H}_{0}$ was rejected. Put simply, the Entre Orientation did influence Knowledge Creation.

How much Entre Orientation influenced Knowledge Creation is represented by the $R$-squared value. The value of $0.594(0.771 \times 0.771)$ indicates that the influence of the Entre Orientation on Knowledge Creation was as much as $59.4 \%$. The other $40.6 \%$ were influenced by other factors.

\section{The Influence of Technology on Knowledge Creation}

$\mathrm{H}_{0}: \gamma_{2}=0$; Technology has no influence on Knowledge Creation;

$\mathrm{H} 0: \gamma_{2} \neq 0$; Technology has influence on Knowledge Creation; 
The obtained equation is as follows:

Knowledge Creation $=0.186^{*}$ Technology, S.E $=0.162$, C.R $=4.593$

This indicates that the coefficient of the exogenous latent variable, Technology, $\left(\xi_{2}\right)$ against the endogenous latent variable, Knowledge Creation, $(\eta)$ was 0.186 , meaning there was a strong correlation between Technology and Knowledge Creation. The observed $t$ value of 4.593 was higher than the critical $t$ value of \pm 1.96 ; therefore, $\mathrm{H}_{0}$ was rejected. This means that Technology influenced Knowledge Creation. How much Technology influenced Knowledge Creation is represented by the $R$-squared value. The value of $0.035(0.186 \times 0.186)$ indicates that the influence of the Entre Orientation on Knowledge Creation was as much as $3.5 \%$. The other $96.5 \%$ were influenced by other factors.

\subsubsection{The Influence of Knowledge Creation on Competitiveness}

$\mathrm{H}_{0}: \gamma_{1}=0$; Knowledge Creation has no influence on Competitiveness;

$\mathrm{H}_{1}: \gamma_{1} \neq 0$; Knowledge Creation has influence on Competitiveness.

The obtained equation is as follows:

Competitiveness $=0.182 \times$ Knowledge Creation, $\mathrm{S} . \mathrm{E}=0.075, \mathrm{C} . \mathrm{R}=2.126$

This equation shows that the coefficient of the exogenous latent variable, Knowledge Creation, ( $\xi$ ) against the endogenous latent variable, Competitiveness, $(\eta)$ was 0.186 , meaning there was a strong correlation between Knowledge Creation and Competitiveness. The observed $t$ value of 2.126 was higher than the critical $t$ value of \pm 1.96 ; therefore, $\mathrm{H}_{0}$ was rejected. This means that Knowledge Creation influenced Competitiveness.

How much Knowledge Creation influenced Competitiveness is represented by the $R$-squared value. The value of $0.033(0.182 \times 0.182)$ indicates that the influence of the Entre Orientation on Knowledge Creation was as much as $3.3 \%$. The other $96.7 \%$ were influenced by other factors. The influence of Entre Orientation, Technology, and Knowledge Creation on competitiveness is represented by the $R$ squared value of 0.665 . This means that Entre Orientation, Technology, and Knowledge Creation influenced Competitiveness as much as $66.5 \%$. The other $33.5 \%$ were influenced by other factors.

\section{Conclusion}

In regard with the result of this study, it can be concluded that the influence of Entre Orientation, Technology, and Knowledge Creation on competitiveness is represented by the R-squared value of 0.665. This means that Entre Orientation, Technology, and Knowledge Creation influenced Competitiveness as much as $66.5 \%$. The other $33.5 \%$ were influenced by other factors. Based on the research finding, SMEs Batik finds it difficult to organize the collection of Explicit Knowledge into a more systematic media, it is due to the lack of media infrastructure to keep the knowledge. In addition, technology adoption is not necessary for handmade batik considering that handmade batik relies on personal skill. Furthermore, Batik SMEs have a potential to compete by offering product quality and differentiation and a risk taker. The other finding also revealed that SMEs Batik expects optimal government support in facilitating SMEs Batik, supporting promotion and marketing and providing competitive model to take SMEs Batik to global market.

\section{References}

Ács, Z. J., \& Audretsch, D. B. (Eds.). (2010). Handbook of entrepreneurship research (pp. 165-182). New York: Springer. 
Apulu, I., \& Latham, A. (2011). Drivers for information and communication technology adoption: a case study of Nigerian small and medium sized enterprises. International Journal of Business and Management, 6(5), 51.

Autio E. (2016). Global Entrepreneurship Index. Washington DC, USA; 2016.

Bozkurt, Ö. Ç., \& Kalkan, A. (2014). Business Strategies of SME's, Innovation Types and Factors Influencing Their Innovation: Burdur Model/KOBI'lerin Isletme Stratejileri, Inovasyon Türleri ve Inovasyonlarini Etkileyen Faktörler: Burdur Modeli. Ege Akademik Bakis, 14(2), 189.

BPS. (2016). Statistik Indonesia.

Carr, J. (2005). The Implementation of technology-based SME management development programmes. Journal of Educational Technology \& Society, 8(3), 206-215.

Cerchione, R., Esposito, E., \& Spadaro, M. R. (2015). The spread of knowledge management in SMEs: A scenario in evolution. Sustainability, 7(8), 10210-10232.

Darbanhosseiniamirkhiz, M., \& Wan Ismail, W. K. (2012). Advanced manufacturing technology adoption in SMEs: An integrative model. Journal of technology management \& innovation, 7(4), $112-$ 120.

Dean, T. J., \& McMullen, J. S. (2007). Toward a theory of sustainable entrepreneurship: Reducing environmental degradation through entrepreneurial action. Journal of business venturing, 22(1), 50 76.

Desouza, K., \& Awazu, Y. (2006). Knowledge management at SMEs: five peculiarities. Journal of Knowledge Management, 10(1), 32-43. doi:10.1108/13673270610650085.

Drucker, P. F. (1985). Innovation and Entrepreneurship, Practice and Principles. New York: Harper \& Row Publisher.

Evangelista, P., Esposito, E., Lauro, V., \& Raffa, M. (2010). The adoption of knowledge management systems in small firms. Electronic Journal of Knowledge Management, 8(1), 33-42.

Ghorbel, F., Hachicha, W., \& Boujelbène, Y. (2017). A mixed approach for studying effectual entrepreneurial opportunities: development and application to Tunisian context. Management Science Letters, 7(9), 439-456.

Hasan, S. (1934). Minister of Sme. Four Problem Increase of Number SMEs in Indonesia. Merdeka.

Industry (2016). Ministry of Industry Accountability Report. Jakarta, Indonesia.

Kadocsa, G. (2006). Research of competitiveness factors of SME. Acta Polytechnica Hungarica, 3(4), 71-84.

Kirzner, I. M. (2015). Competition and entrepreneurship. University of Chicago press.

Raf, M. (2000). Studi Pada Sentra Industri Kecil Batik Di Kota Jambi. Manaj dan Keirausahaan., 14(1999), 91-101.

Rrustemi, V. (2011). Organizational learning and knowledge creation processes in SMEs. Journal of Knowledge Management, Economics \& Information Technology, 1(6), 168-188.

Nonaka, I., \& Lewin, A.Y. (1994). Dynamic theory knowledge of organizational creation. Organization Science, 5(1), 14-37.

Schumpter, J. (1934). The Theory of Economic Development. Cambridge: MA : Harvard University Press.

Singer, S., Amorós, E., \& Moska, D. (2015). Global Entrepreneurship Monitor - 2014 Global Report.

Wu, K. F. (2015). An Empirical Study of Small-and-Medium-Sized Firms in Taiwan: Entrepreneurship, Core Copetency and Market Performance. Web Journal of Chinese Management Review, $18(3), 1$.

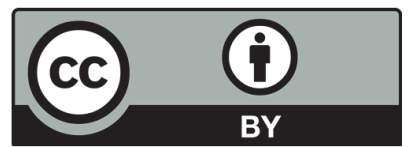

(C) 2018 by the authors; licensee Growing Science, Canada. This is an open access article distributed under the terms and conditions of the Creative Commons Attribution (CC-BY) license (http://creativecommons.org/licenses/by/4.0/). 